Original Research Paper

\title{
Characterization of Crude Polyphenol Oxidase Activity in Buckwheat Sprouts
}

\author{
${ }^{1}$ Yuedong Song, ${ }^{1}$ Yangfang Zhang, ${ }^{1}$ Yilin Wang, ${ }^{1}$ Jin Zhang, ${ }^{1}$ Fei Wang, \\ ${ }^{1.2}$ Guanglei Chu, ${ }^{1}$ Haifang Xiao and ${ }^{1.2}$ Xia Sun \\ ${ }^{1}$ School of Agricultural Engineering and Food Science, Shandong University of Technology, Zibo, China \\ ${ }^{2}$ Shandong Provincial Engineering Research Center of Vegetable Safety and Quality Traceability, 255049, Shandong China
}

\author{
Article history \\ Received: 07-02-2021 \\ Revised: 12-05-2021 \\ Accepted: 18-05-2021 \\ Corresponding Author: \\ Yuedong Song \\ School of Agricultural \\ Engineering and Food Science, \\ Shandong University of \\ Technology, Zibo, China \\ E-mail: 932327165@qq.com
}

\begin{abstract}
Buckwheat sprouts can not only effectively reduce the trypsin inhibitor in buckwheat grain, but also improve the content of bioactive ingredients such as flavonoids and other effective components. However, Polyphenol Oxidase (PPO) in buckwheat sprouts causes browning of food, which limits the application of buckwheat sprouts in food. In addressing this problem, studying the characteristics of PPO in buckwheat sprouts is necessary. PPO in buckwheat sprouts was first studied by germinating buckwheat sprouts as raw material for 10 days. Results showed that the optimum temperature and $\mathrm{pH}$ of PPO in buckwheat sprouts were $32^{\circ} \mathrm{C}$ and 7.2 , respectively. PPO had specificity to substrates. The catalytic capacity of PPO with pyrogallic acid was higher than that of catechol, which had weak catalytic capacity of hydroquinone and resorcinol and no catalytic capacity to gallic acid. PPO showed strong thermal stability because its relative activity remained $23.1 \% \pm 1.69 \%$ even heating at $90^{\circ} \mathrm{C}$ for $30 \mathrm{~min}$. Ascorbic acid, L-cysteine, sodium hydrogen sulfite and sodium sulfite all had significant inhibition effect on PPO activity. The best inhibitor was ascorbic acid, whereas citric acid and Ethylenediaminetetraacetic acid disodium salt had no evident effect. The PPO activity was inhibited at a low concentration of $\mathrm{Cu}^{2+}$ and $\mathrm{Mg}^{2+}(0-1 \mathrm{~mm})$ and it can be significantly activated at a higher concentration $(5-50 \mathrm{~mm})$ by adding $\mathrm{AL}^{3+}$, whereas no significance was observed when adding $\mathrm{Ca}^{2+}$. This study can provide reliable theoretical support for avoiding browning of buckwheat sprouts during food processing.
\end{abstract}

Keywords: Polyphenol Oxidase, Buckwheat Sprouts, Enzyme Characteristics, Kinetic Characteristics, Inhibitor

\section{Introduction}

Buckwheat belongs to the Polygonaceae annual dicotyledon plant, which is a kind of homology of medicine and food (Song et al., 2020). Buckwheat is rich in nutrition, which contains phytosterols, linoleic acid and flavonoids; thus, buckwheat can decrease glucose, prevent cardiovascular diseases and tumor and improve other physiological functions (Zhu, 2016). However, buckwheat seed contains trypsin inhibitors, thereby affecting the absorption of buckwheat nutrients and excessive consumption can cause abdominal distension and other uncomfortable symptoms (Dunaevsky et al., 1998).

Buckwheat sprouts refer to the buckwheat seedlings that germinate for approximately 10-14 days. These sprouts are popular because of its tender and attractive flavor without any bean flavor. The nutrients of buckwheat sprouts change during cultivation; trypsin inhibitors disappear or trace levels occur when buckwheat sprouts are cultured for 10 days and the amino acids become more balanced. The amino acid ratio coefficient is closed to the eggs, which is more conducive to body's absorption of buckwheat protein. In addition, the total flavonoid content is 6.5 times that of buckwheat seed (Almuhayawi et al., 2021). Moreover, the carbohydrate composition of buckwheat sprouts increases the monosaccharide level while decreasing the proportion of disaccharide and trisugar. The linoleic acid and total unsaturated fatty acids during buckwheat germination for 7 days' increase by 52.1 and $83 \%$ and linoleic acid significantly reduces the occurrence of cardiovascular and cerebrovascular diseases (Kim et al., 2004). Deepprocessed products of buckwheat sprouts have been developed, such as buckwheat sprout yoghurt, buckwheat 
sprout milk drink, buckwheat sprout steamed bread, buckwheat sprout vinegar and buckwheat bud tea, to make better use of buckwheat sprouts. Buckwheat sprouts brown during the processing of buckwheat bud cookies and bread, which affects the quality of products and reduces the nutrition of products.

Polyphenol Oxidase (PPO), a common browning factor, is widely found in plants. Its characteristics are different because of the different species and varieties. During storage and processing, it affects the browning of fruit and vegetables and sensory properties also affect the marketability of products (Han et al., 2019). Given the effect of PPO on fruit and vegetables after harvesting, different characteristics of PPO in many fruit and vegetables, such as Lycium barbarum L., blueberry, pear and cape gooseberry, have been studied (Zhu et al., 2020; Siddiq and Dolan, 2017; Bravo and Osorio, 2016). Based on previous studies, the characteristic of PPO for different plants is similar and distinct. To date, the characteristics of PPO in buckwheat sprouts have not been reported. Studying the PPO in buckwheat sprouts is necessary to make better use of buckwheat sprouts.

This study analyzed the activity of PPO extracted from buckwheat sprouts, evaluated the characteristic at different temperatures and $\mathrm{pH}$ range, determined the kinetic parameters and thermal stability and studied the inhibitors and activators. It's will be beneficial to effectively reduce the occurrence of discoloration in buckwheat sprouts juices and provide theoretical support for the application of buckwheat sprouts in food processing.

\section{Materials and Methods}

\section{Materials}

Buckwheat was collected from Zhaozhuang Village, Yuezhuang Town, Yiyuan County, Shandong Province. Buckwheat was grown in sandy loam soil, harvested naturally after maturity and dried in a refrigerator at $-18^{\circ} \mathrm{C}$. Biochemical reagents were purchased from Shanghai Yuanye Biological Products Co., Ltd (Shanghai, China) and other chemical reagents were of analytical grade.

\section{Experimental Methods}

\section{Preparation of Buckwheat Sprouts}

The production process of buckwheat sprouts is illustrated in Fig. 1. In brief, after cleaning, the buckwheat was placed in a constant-temperature incubator at $35^{\circ} \mathrm{C}$ for 1 day. When the radicles break through the seed coat, they were sown in a seedling tray with two layers of filter paper. The seeds were covered with ceramic puffed balls with a diameter of $3 \mathrm{~mm}$ and the coverage depth was 2 $\mathrm{cm}$. The relative humidity of the environment was about $88 \%$ and seed was protected from light for 2 days. Then,
LED was used to supplement the light, with light intensity of 800-1000 LX and time of $12 \mathrm{~h}$. The temperature was kept at $28^{\circ} \mathrm{C}$ during the day and the water spray was kept moist two times a day. Finally, the sprouts were harvested after 7 days of light supplement.

\section{Preparation of Buckwheat Crude PPO}

The extraction method was based on Zhu et al. (2020) with some modifications. In brief, $80 \mathrm{~g}$ of buckwheat sprouts was added into a solution of $5 \%$ polyvinylpyrrolidone in $240 \mathrm{~mL}$ of phosphate buffer $(0.05$ $\mathrm{M}, \mathrm{pH}$ 7.2) and quickly ground into slurry on ice bath. Afterward, the mixture was digested for $2 \mathrm{~h}$ at $4^{\circ} \mathrm{C}$ and then filtered through four layers of gauze. Finally, the mixture was centrifuged for $15 \mathrm{~min}$ at $10,000 \mathrm{~g}$ and $4{ }^{\circ} \mathrm{C}$ (TGL-20M high-speed bench-refrigerated centrifuge). The supernatant was filtered through a $0.45 \mu \mathrm{m}$ microporous membrane to obtain the crude enzyme solution and then the enzyme was placed in a $1000 \mathrm{~mL}$ brown volumetric flask and diluted with phosphoric acid buffer (PBS,0.05 M, pH 7.2) to volume. The PPO solution was added with $0.225 \mathrm{mg} / \mathrm{mL}$ of protein by the Coomassie Brilliant Blue R250 method and stored at $4{ }^{\circ} \mathrm{C}$ for later use.

\section{Method for Determining Enzyme Activity}

The enzyme activity was assayed on the basis of Han et al. (2019) with some modifications by a UV2550-type double-beam ultraviolet spectrophotometer (Shimadzu). Clean test tubes were used and added with $2 \mathrm{~mL}$ of PBS (pH 7.2, $0.05 \mathrm{M}$ ), followed by catechol $(0.1 \mathrm{M})$ and crude enzyme solution $(0.2 \mathrm{~mL})$. The mixture was shaken quickly and absorbance was measured at $420 \mathrm{~nm}$ with control of the blank without the crude enzyme solution. The value was recorded every 0.5 for $3 \mathrm{~min}$. The relation curve between absorbance and reaction time was made and change of 0.001 of $\mathrm{OD}_{420 \mathrm{~nm}}$ per gram fresh weight per minute was used as an enzyme activity unit (U/g.min).

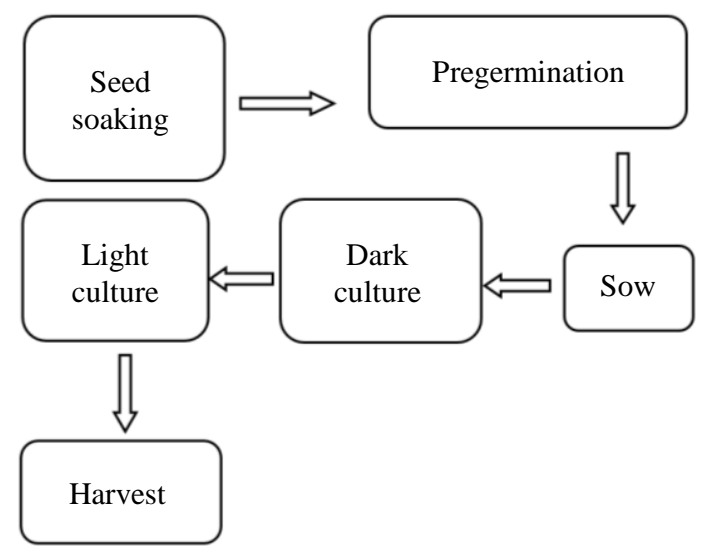

Fig. 1: Production process of buckwheat sprouts 


\section{Selection of the Optimal $\mathrm{pH}$}

One milliliter of $0.1 \mathrm{M}$ catechol was added to $2 \mathrm{~mL}$ of PBS $(0.05 \mathrm{M})$ with different $\mathrm{pH}$ to determine the optimal $\mathrm{pH}$ and $0.2 \mathrm{~mL}$ of enzyme solution was added to the reaction system. The optimum $\mathrm{pH}$ for the maximum enzyme activity was used for other subsequent experiments (Zaini et al., 2013).

\section{Optimal Temperature and Temperature Stability}

One milliliter of catechol $(0.1 \mathrm{M})$ was added into $2 \mathrm{~mL}$ of PBS ( $\mathrm{pH} 7.2$ ) to determine the optimal reaction temperature and then bathed in a water bath at different temperatures (20$60^{\circ} \mathrm{C}$ ) for $5 \mathrm{~min}$ (Zaini et al., 2013). Afterward, $0.2 \mathrm{~mL}$ of crude enzyme solution at $4^{\circ} \mathrm{C}$ was added quickly and the enzyme activity of each treatment was measured.

The crude enzyme solution was placed in a water bath at different temperatures $\left(60,65,70,75,80,85\right.$ and $\left.90^{\circ} \mathrm{C}\right)$ for different time $(5,10,15$ and $30 \mathrm{~min})$ to determine the thermal stability of the enzyme. Afterward, the sample was quickly cooled to room temperature with ice water. Then, $0.2 \mathrm{~mL}$ of crude enzyme solution was added into 2 $\mathrm{mL}$ of PBS solution (0.05 M, pH 7.2) and $1 \mathrm{~mL}$ of catechol $(0.1 \mathrm{M})$ was added and then its catalytic activity was measured (Zaini et al., 2013).

\section{Substrate-Specific Selection and Enzyme Kinetics}

Different substrates (hydroquinone, catechol, resorcinol, gallic acid and pyrogallic acid) with a concentration of $0.1 \mathrm{M}$ were dissolved in PBS solution (0.05 M, pH 7.2) to determine the catalytic capacity of buckwheat sprout PPO.

Different concentrations (0-0.22 M) of pyrogallic acid and catechol solution were prepared to determine the effect of substrate concentration on the activity of buckwheat sprout PPO. Then, the enzyme activities were determined. Using the Lineweaver-Burk mapping method, the reciprocal of the substrate concentration $(1 / \mathrm{S})$ was the abscissa and the reciprocal of the enzyme reaction rate $(1 / \mathrm{V})$ was the ordinate. The Michaelis constant $(\mathrm{Km})$ was calculated and the maximum speed of enzyme catalysis ( $\left.\mathrm{V}_{\max }\right)$ was determined (Yu et al., 2019).

\section{Selection of Inhibitors}

The inhibitory effect of different concentrations for several inhibitors on the PPO activity was determined. The reaction system was added with $0.2 \mathrm{~mL}$ of inhibitor solution and their enzyme activity was measured. The enzyme activity of the sample without inhibitor was recorded as $100 \%$ and the relative enzyme activity of each inhibitor was calculated (Siddiq and Dolan, 2017).

\section{Metal Ion Action}

The metal ions, namely, calcium ion $\left(\mathrm{Ca}^{2+}\right)$, magnesium ion $\left(\mathrm{Mg}^{2+}\right)$, copper ion $\left(\mathrm{Cu}^{2+}\right)$ and aluminum ions $\left(\mathrm{AL}^{3+}\right)$, were prepared at four different concentrations. When $1 \mathrm{~mL}$ of catechol $(0.1 \mathrm{M}), 0.2 \mathrm{~mL}$ of PPO solution and $0.2 \mathrm{~mL}$ of metal ion solution were added into $2 \mathrm{~mL}$ of PBS (0.05 M, pH 7.2), the enzyme activity was measured (Guo et al., 2009). Relative enzyme activity of adding different metal ions was calculated by using $100 \%$ of the sample without metal ions.

\section{Statistical Analysis}

The experiment was repeated three times and the results were analyzed by Origin 8.0.

\section{Results and Discussion}

\section{Effect of $p H$ on PPO}

The $\mathrm{pH}$ of the reaction system had a great influence on PPO activity (Fig. 2). PPO activity increased linearly with $\mathrm{pH}$ between 5.8 and 7.0. The $\mathrm{pH}$ range of suitable activity was 7.0-7.4 and the optimum $\mathrm{pH}$ was 7.2. When $\mathrm{pH}$ was 7.6, the PPO activity decreased sharply to $73.19 \%$, whereas the PPO activity was only $17.67 \%$ of the maximum activity when $\mathrm{pH}$ was 8.5 . The results indicated that PPO activity decreased more evidently in alkaline solution compared with acidic solution. The browning degree of buckwheat sprouts can be controlled by adjusting the acidity and alkalinity of the environment in production. Similarly, Jhonatam's study on Buriti (Mauritia flexuosa Linnaeus F.) fruit found that the optimal $\mathrm{pH}$ value was 7.0 (de Oliveira Carvalho and Orlanda, 2017). However, Bravo reported that the optimum $\mathrm{pH}$ for cape gooseberry PPO was 5.5 (Bravo and Osorio, 2016), whereas Mengyao Wu reported that the optimum $\mathrm{pH}$ for Camellia sinensis var. Assamica CV. was 4.5 (Wu et al., 2017). These differences were caused by different enzymes from diverse plants.

\section{Effect of Temperature on PPO Activity and Thermal Stability}

Figure 3 shows the effect of temperature $\left(20-60^{\circ} \mathrm{C}\right)$ on PPO activity. The PPO activity was maximum when the temperature was $32^{\circ} \mathrm{C}$. When the temperature was lower than $32^{\circ} \mathrm{C}$, the PPO activity decreased rapidly with the decrease of temperature and when the temperature was higher than $32^{\circ} \mathrm{C}$, the activity decreased, but the decrease was relatively moderate. Although the temperature was $60^{\circ} \mathrm{C}$, the activity was approximately $60 \%$ of the maximum, which indicated that the PPO of buckwheat sprout was an enzyme with a strong thermal stability. This result was similar to the best reaction temperature of PPO in blueberry reported in previous studies (Siddiq and Dolan, 2017), which proved that the best PPO reaction temperature of blueberry was $35^{\circ} \mathrm{C}$. Meanwhile, this result was different from that of artichoke in previous studies (Doğan et al., 2005). The optimal reaction temperature of artichoke was $40^{\circ} \mathrm{C}$. 
The thermal stability of PPO in buckwheat sprouts was stable (Fig. 4). Even when heating to $90^{\circ} \mathrm{C}$ for $30 \mathrm{~min}$, PPO activity can still maintain $30 \%$. Heating time showed a stronger effect than temperature on PPO activity, with the same treatment time and no significant difference was observed in PPO activity from 60 to $70^{\circ} \mathrm{C}$ and from 80 to $90^{\circ} \mathrm{C}$. However, $75^{\circ} \mathrm{C}$ was a sensitive temperature, which was significantly different from other temperatures for the same treatment time. Therefore, PPO activity cannot be inhibited by heating in production because PPO activity still remained $23.1 \% \pm 1.69 \%$ at $90^{\circ} \mathrm{C}$ for $30 \mathrm{~min}$. This result was similar to the conclusion of pineapple puree PPO activity reported by Chutintrasri and Noomhorm (2006), but it was different from the honeydew peach reported by Liu et al. (2015), whose enzyme activity remained only $8.9 \%$ after $140 \mathrm{~s}$ of heat treatment at $80^{\circ} \mathrm{C}$.

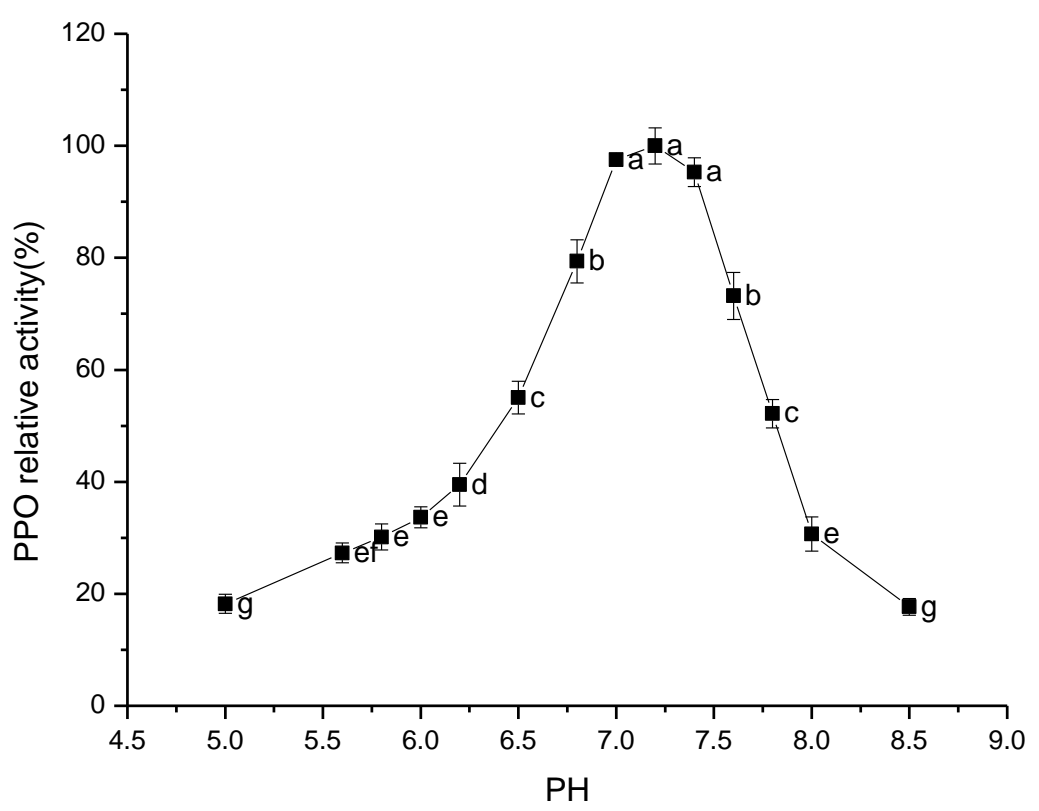

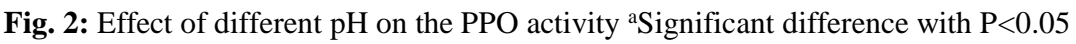

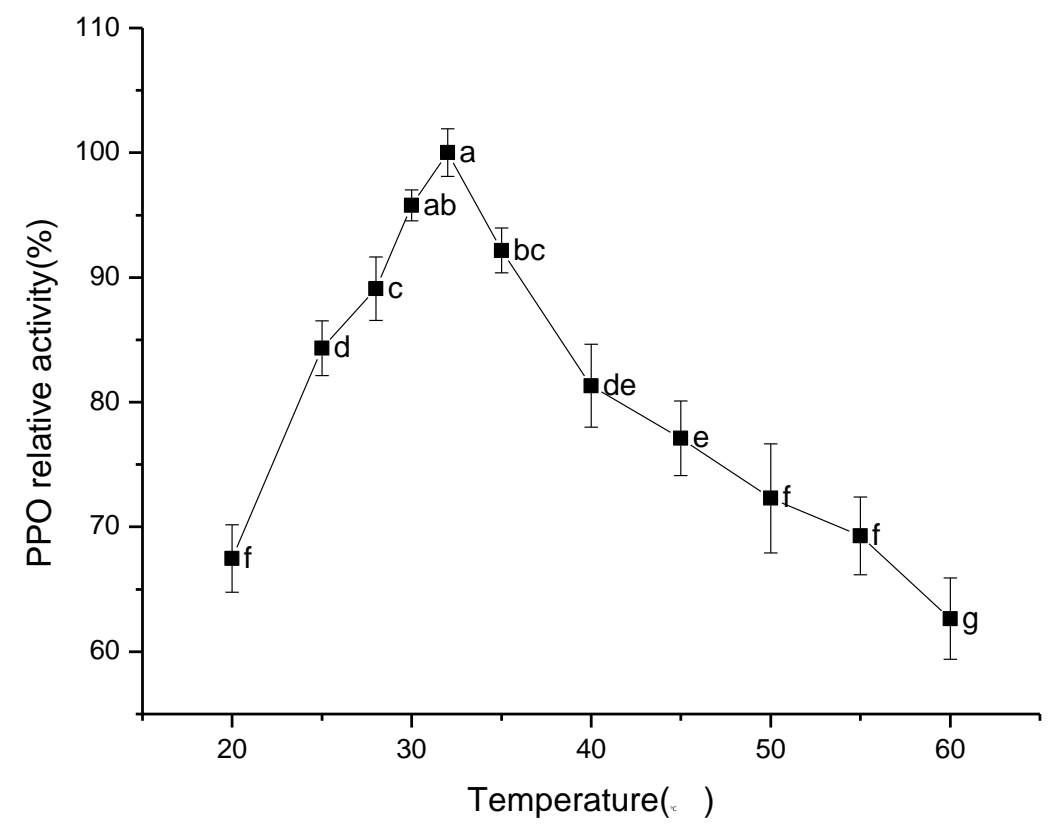

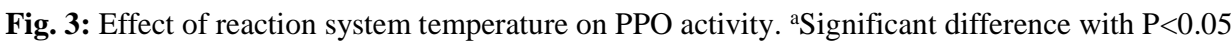




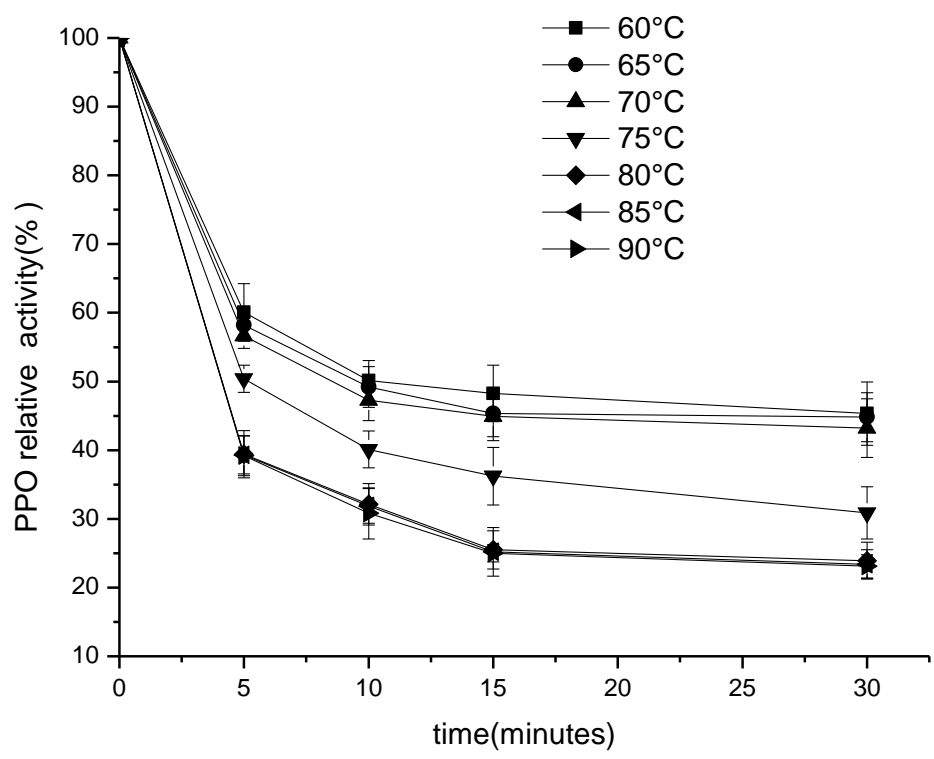

Fig. 4: Thermal stability of PPO in buckwheat sprouts

Table 1: substrate specificity of buckwheat sprouts PPO

\begin{tabular}{ll}
\hline Substrates & PPO activity \\
\hline Resorcinol & $9.69 \pm 0.34^{\mathrm{c}}$ \\
Catechol & $27.73 \pm 0.24^{\mathrm{b}}$ \\
Hydroquinone & $9.34 \pm 0.4^{\mathrm{c}}$ \\
Gallic acid & $1.84 \pm 0.35^{\mathrm{d}}$ \\
Pyrogallic acid & $100^{\mathrm{a}}$ \\
\hline
\end{tabular}

${ }^{1}$ Relactive to pyrogallic acid as 100

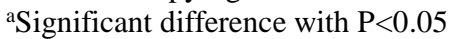

\section{Effects of Different Reaction Substrates on PPO Activity}

Table 1 shows that the PPO had different catalytic capacities for different substrates. The PPO of buckwheat sprouts had no catalytic ability to gallic acid and weak catalytic ability to resorcinol and hydroquinone and the activity of catechol was nearly three times for hydroquinone. The highest activity was pyrogallic acid, indicating that the buckwheat sprout PPO could catalyze the ortho phenol, whereas the buckwheat sprout PPO had no or little ability to catalyze the meto-phenols and paraphenols, which was consistent with the research conclusions of Cheemar on Ataulfo Mango (Cheema and Sommerhalter, 2015) and Zaini's studies on Snake Fruit (Zaini et al., 2013). However, Siddiq had different conclusions on the study of blueberry PPO and Siddiq concluded that the catalytic effect of pyrogallic acid on blueberry PPO was lower than that on catechol (Siddiq and Dolan, 2017). In this study, buckwheat sprout PPO had the strongest catalytic ability to pyrogallic acid.

According to the Lineweaver-Burk double-reciprocal curve (Fig. 5), the kinetic equation of buckwheat sprout PPO with pyrogallic acid and catechol as substrate was presented as follows: $1 / \mathrm{V}=0.00006(1 / \mathrm{S})+0.0004$ and
$1 / \mathrm{V}=0.00002(1 / \mathrm{S})+0.0014 . \mathrm{K}_{\mathrm{m}}$ was 0.154 and $0.175 \mathrm{M}$ and $\mathrm{V}_{\max }$ was 2445.59 and $735.29 \mathrm{U} / \mathrm{g} \cdot \mathrm{min}$.

\section{Inhibition Effect of Inhibitors on PPO}

The types and concentrations of inhibitors had different effects on the inhibition of PPO (Fig. 5). With the increase of ascorbic acid concentration (0.1-0.5 mm), PPO relative activity decreased from $82.9 \%$ to $5.3 \%$, when the concentration of ascorbic acid reached $1 \mathrm{~mm}$, PPO activity could be completely inhibited during the test. Sodium hydrogen sulfite also showed a similar pattern. When the concentration reached $0.5 \mathrm{~mm}$, the relative activity of PPO was only 14\%. Although the inhibitory effect of sodium sulfite was not as good as that of sodium hydrogen sulfite, the relative activity of PPO remained only $23.4 \%$ when the concentration increased to $1.5 \mathrm{~mm}$, which remarkably inhibited the activity of PPO. Lcysteine containing thiol groups has always been a commonly used PPO inhibitor and it also played an important role in this study. When the concentration was 1 $\mathrm{mm}$, the relative activity of PPO was only $9.8 \%$ (Fig. 6A). However, the effect of citric acid was not evident. When the concentration was as high as $60 \mathrm{~mm}$, PPO activity remained $36 \%$. Similar to EDTA-2Na, when the concentration was as high as $30 \mathrm{~mm}$, the PPO activity still remained $56 \%$, indicating that citric acid and EDTA-2Na were not suitable to be PPO inhibitors of buckwheat sprouts (Fig. 6B).

Ascorbic acid was the best inhibitor of PPO in buckwheat sprouts, followed by sodium hydrogen sulfite and L-cysteine, whereas citric acid and EDTA$2 \mathrm{Na}$ had no evident effect on PPO. Buckwheat sprout PPO activity can be inhibited by adding $0.5 \mathrm{~mm}$ of ascorbic acid in production. 


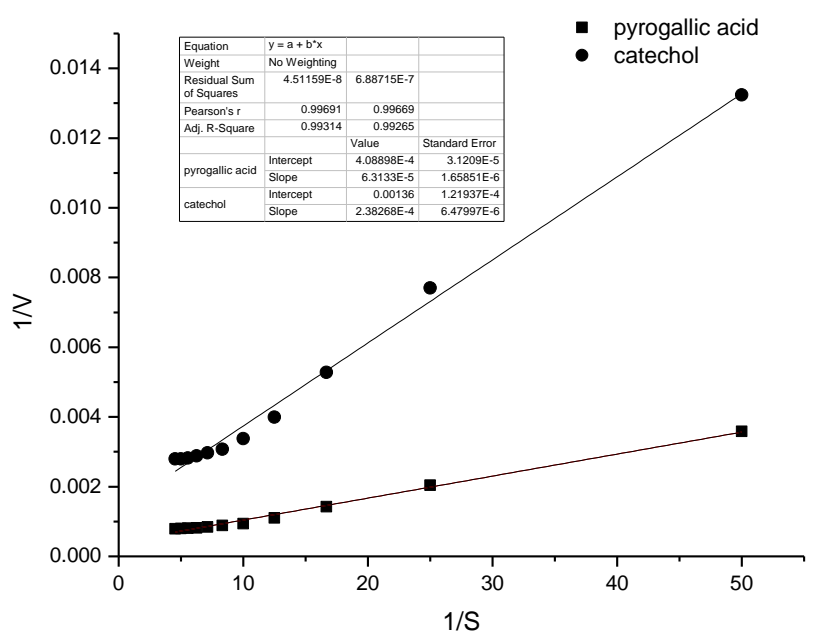

Fig. 5: Diagrams of double reciprocal relation

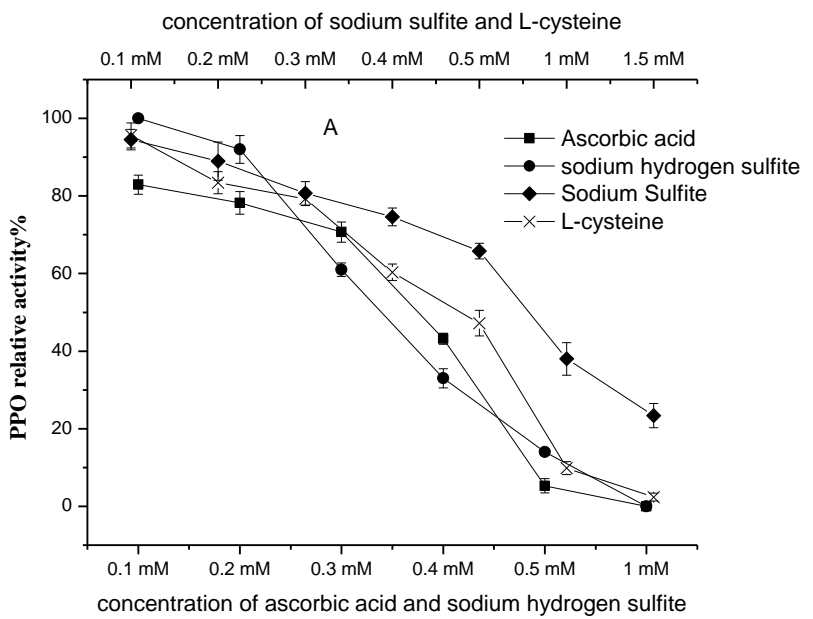

(a)

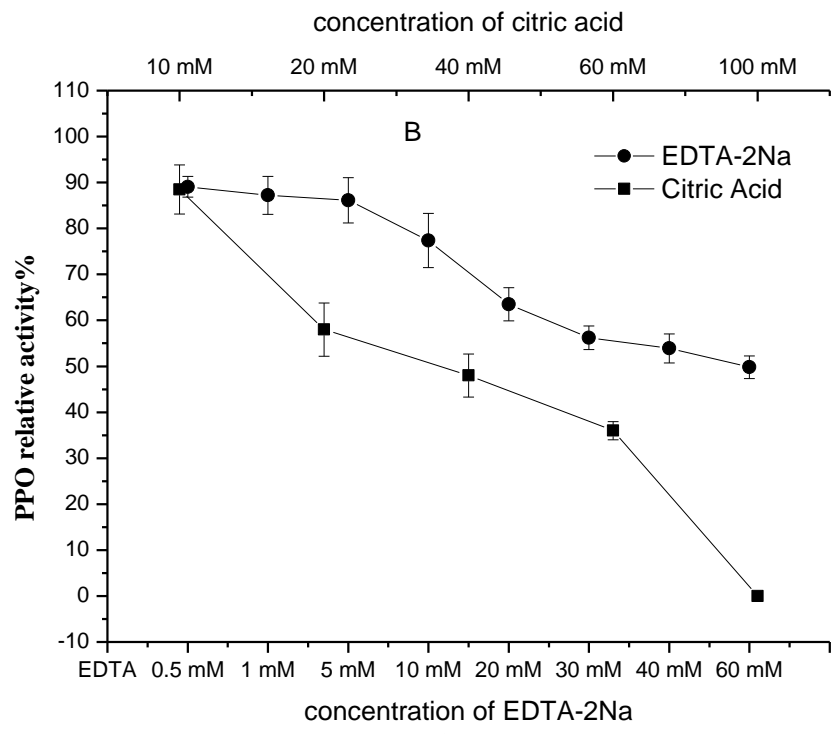

(b)

Fig. 6: Inhibition effect of different inhibitors on PPO 
Previous studies have reported that the same inhibitors had different inhibitory effects on the activity of PPO from diverse sources. Batista reported that the PPO inhibition rate of L-cysteine $(10 \mathrm{~mm})$ on Solanum lycocarpum fruits was $74.5 \%$ higher than that of ascorbic acid $(30 \mathrm{~mm})$, which was $70.3 \%$ (Batista et al., 2014). Ionită reported that the inhibition rate of ascorbic acid (5 $\mathrm{mm}$ ) on plum PPO was $100 \% \pm 0.36 \%$, but the inhibition rates of L-cysteine and citric acid at the same concentration were $37.74 \% \pm 1.6 \%$ and $32.18 \% \pm 1.71 \%$, respectively (Ioniţă et al., 2017), which was different from our conclusion. Guo reported that the activity of PPO in green bean was only $0.7 \% \pm 0.004 \%$ when $1 \mathrm{~mm}$ of ascorbic acid was added, whereas it was $1.7 \% \pm 0.3 \%$ and $90.0 \% \pm 1.6 \%$ when L-cysteine and citric acid were added with the same concentration, respectively (Guo et al., 2009), which was similar to our results. In the study of PPO in Cleome gynandra L. leaves, Gao reported that the PPO activity remained $85 \% \pm 1 \%, 0$ and $0.73 \% \pm 1 \%$ when citric acid, L-cysteine and EDTA were added at concentrations of $1 \mathrm{~mm}$, respectively (Gao et al., 2011). In this study, citric acid and EDTA-2Na could inhibit PPO activity only at a relatively high concentration; however, in the study of PPO in Mamey by Gisela, when $1 \mathrm{~mm}$ of citric acid and $10 \mathrm{~mm}$ of EDTA were added, the relative activity of PPO was 137 and 114\%, respectively (PalmaOrozco et al., 2011), which was significantly different from our research conclusion. Therefore, inhibitors should be selected differently for different plants.

\section{Effects of Metal Ions on PPO Activity}

Metal ions in the storage environment can affect the activity of PPO. Two copper ions $(\mathrm{CuA}$ and $\mathrm{CuB})$ are identified in the PPO molecule and the two copper ions are combined with three histidine residues to form the active center of PPO (Ma et al., 2016). If metal ions in the environment interact with enzyme proteins or substrates, then the enzymatic reaction speed among them will be affected. During production, the environment is rich in a variety of metal ions (tap water is rich in $\mathrm{Ca}^{2+}$ and $\mathrm{Mg}^{2+}$ and $\mathrm{Al}^{3+}$ is commonly found in additives). In addition, PPO contains $\mathrm{Cu}^{2+}$. Therefore, this study selects these four metal ions as the research object. The effect of metal ions on the PPO activity of buckwheat bud is shown in Fig. 7. As shown in the figure, PPO activity was inhibited when $\mathrm{Mg}^{2+}$ concentration was $0-1 \mathrm{~mm}$, but it increased with the increase in concentration and reached $127.65 \%$ when the concentration of $\mathrm{Mg}^{2+}$ was $50 \mathrm{~mm}$. $\mathrm{Ca}^{2+}$ increased the activity of PPO in buckwheat sprouts, but no significant difference was observed in this increase. Moreover, no significant difference was observed among different concentrations $(P<0.05)$, which was inconsistent with Guo conclusion on green beans. Guo concluded that the relative activity of PPO in green beans was $209.4 \% \pm 2.1 \%$ when adding $10 \mathrm{~mm}$ of $\mathrm{Ca}^{2+}$ (Guo et al., 2009).

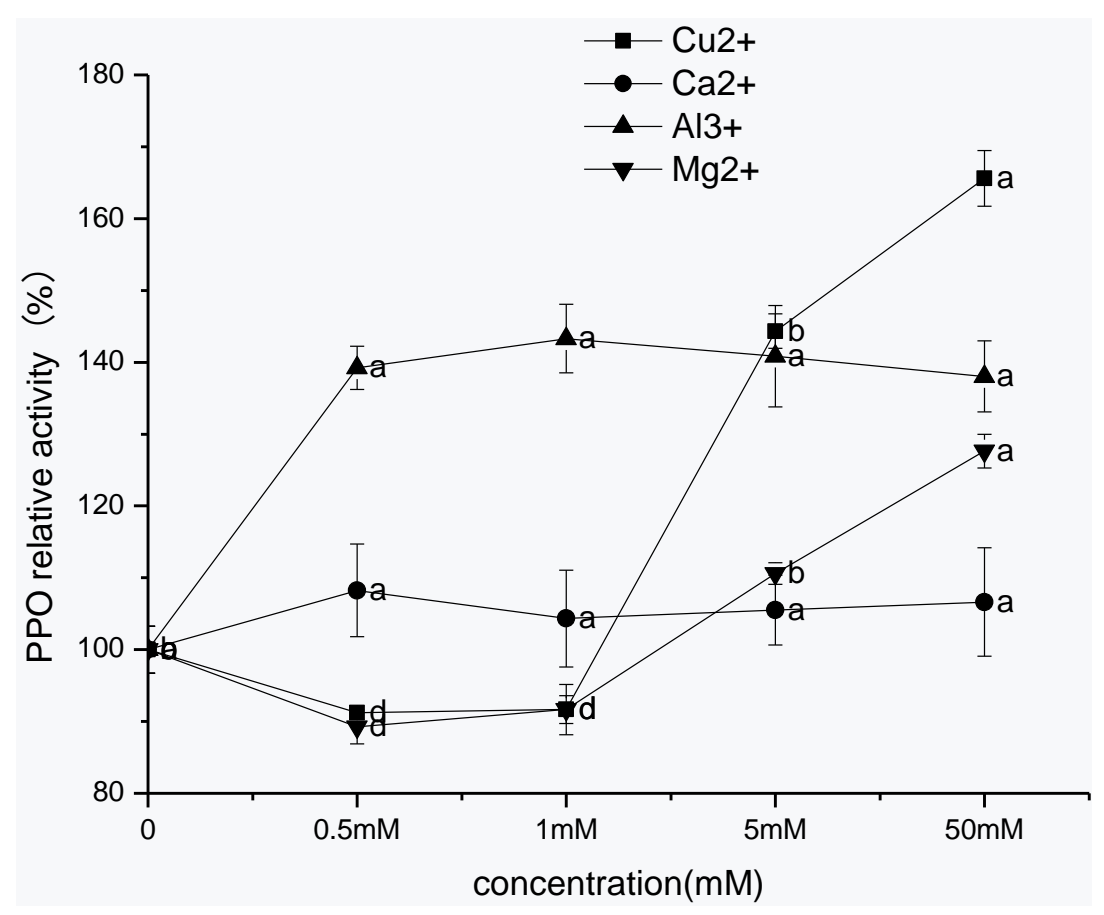

Fig. 7: Effects of different metal ions on PPO activity a Significant difference with $\mathrm{P}<0.05$ 
All concentrations of $\mathrm{AL}^{3+}$ had a significant activation effect on PPO activity and the PPO relative activity was as high as $132.91 \%$ even with a low concentration of 0.5 $\mathrm{mm}$, but no significant difference was observed among different concentrations $(P<0.05)$. When the concentration was between 0 and $1 \mathrm{~mm}, \mathrm{Cu}^{2+}$ had an inhibitory effect on the PPO activity; however, with the increase of concentration, the PPO activity was significantly activated and when the concentration was 5 and $50 \mathrm{~mm}$, the PPO relative activity was significantly increased to 144.33 and $165.6 \%(P<0.05)$. The effect of $\mathrm{Cu}^{2+}$ and $\mathrm{AL}^{3+}$ was different from that of Dysosma verispellis (Hance.) M. Cheng PPO by He. He's conclusion indicated that $\mathrm{Cu}^{2+}$ and $\mathrm{AL}^{3+}$ had an activation effect at low concentration, whereas the increase of concentration showed an inhibition effect (He et al., 2015). Considering that the structure of PPO contained $\mathrm{Cu}^{2+}, \mathrm{Cu}^{2+}$ may combine with other parts of PPO in addition to the PPO catalytic active center, thereby affecting the enzyme activity, which needed further verification by experiments.

\section{Conclusion}

In this paper, the characteristics of PPO in buckwheat sprouts were studied comprehensively, including $\mathrm{pH}$, temperature and thermal stability, substrate specificity, enzyme reaction kinetics, inhibitors and activators. The results showed that pyrogallic acid was the best substrate for buckwheat sprout PPO, followed by catechol. The optimal $\mathrm{pH}$ was 7.2 and the optimal temperature was $32^{\circ} \mathrm{C}$. The PPO had strong thermal stability and its enzyme activity remained $23.1 \% \pm 1.69 \%$ after $30 \mathrm{~min}$ at $90^{\circ} \mathrm{C}$. Ascorbic acid was the optimal inhibitor of PPO activity. PPO activity was inhibited by a low concentration of $\mathrm{Cu}^{2+}$ and $\mathrm{Mg}^{2+}(0-1 \mathrm{~mm})$, whereas it was significantly activated at a higher concentration (5-50 $\mathrm{mm}$ ) and was significantly activated by adding $\mathrm{AL}^{3+}$.

Therefore, the activity of PPO in buckwheat sprouts could be reduced by adjusting $\mathrm{pH}$ and adding $0.5 \mathrm{~mm}$ ascorbic acid and the enzyme activity could not be inactivated by heat treatment methods such as bleaching soup. Furthermore, attention should be paid to avoid contact with $\mathrm{Cu}^{2+}, \mathrm{Mg}^{2+}$ and $\mathrm{AL}^{3+}$ during production.

At present, few studies have been conducted on buckwheat sprouts and the study on buckwheat sprout PPO has not been reported. In this study, the characteristics of buckwheat sprout PPO were systematically studied from many aspects, which will provide theoretical support for the production, storage and deep processing of buckwheat sprouts. This study also provided the possibility for the dietary diversification of diabetic and hypertensive patients. The study of molecular structure may explain the good thermal stability of buckwheat sprout PPO, which should be confirmed by related studies in the future. Furthermore, good thermal stability showed potential as a thermal indicator of some biosensors (de Oliveira Carvalho and Orlanda, 2017), which is one of the directions of subsequent studies.

\section{Acknowledgement}

The Food Science Laboratory of Shandong University of Technology provided support for this research.

\section{Author's Contributions}

Yuedong Song: Participated in the whole experiment process and also contributed to the interpretation of the results and manuscript preparation.

Yanfang Zhang: Participated in part of the experimental design.

Jin Zhang and Yilin Wang: Data curation.

Fei Wang and Guanglei Chu: Ameliorated the manuscript.

Haifang Xiao: Contributed to the study design, the interpretation of the results and manuscript preparation.

Xia Sun: Contributed to the guidance of experimental design and ameliorated the manuscript.

\section{Ethics}

This article is original and contains unpublished material. The corresponding author confirms that all of the other authors have read and approved the manuscript and no ethical issues involved.

\section{References}

Almuhayawi, M. S., Hassan, A. H., Abdel-Mawgoud, M., Khamis, G., Selim, S., Al Jaouni, S. K., \& AbdElgawad, H. (2021). Laser light as a promising approach to improve the nutritional value, antioxidant capacity and anti-inflammatory activity of flavonoid-rich buckwheat sprouts. Food Chemistry, 345, 128788. https://doi.org/10.1016/j.foodchem.2020.128788

Batista, K. A., Batista, G. L., Alves, G. L., \& Fernandes, K. F. (2014). Extraction, partial purification and characterization of polyphenol oxidase from Solanum lycocarpum fruits. Journal of Molecular Catalysis B: Enzymatic, 102, 211-217. https://doi.org/10.1016/j.molcatb.2014.02.017

Bravo, K., \& Osorio, E. (2016). Characterization of polyphenol oxidase from Cape gooseberry (Physalis peruviana L.) fruit. Food Chemistry, 197, 185-190. https://doi.org/10.1016/j.foodchem.2015.10.126

Cheema, S., \& Sommerhalter, M. (2015). Characterization of polyphenol oxidase activity in Ataulfo mango. Food Chemistry, 171, 382-387. https://doi.org/10.1016/j.foodchem.2014.09.011 
Chutintrasri, B., \& Noomhorm, A. (2006). Thermal inactivation of polyphenoloxidase in pineapple puree. LWT-Food Science and Technology, 39(5), 492-495. https://doi.org/10.1016/j.lwt.2005.04.006

de Oliveira Carvalho, J., \& Orlanda, J. F. F. (2017). Heat stability and effect of $\mathrm{pH}$ on enzyme activity of polyphenol oxidase in buriti (Mauritia flexuosa Linnaeus f.) fruit extract. Food Chemistry, 233, 159-163. https://doi.org/10.1016/j.foodchem.2017.04.101

Doğan, S., Turan, Y., Ertürk, H., \& Arslan, O. (2005). Characterization and purification of polyphenol oxidase from artichoke (Cynara scolymus L.). Journal of Agricultural and Food Chemistry, 53(3), 776-785. https://doi.org/10.1021/jf049053g

Dunaevsky, Y. E., Pavlukova, E. B., Beliakova, G. A., Tsybina, T. A., Gruban, T. N., \& Belozersky, M. A. (1998). Protease inhibitors in buckwheat seeds: comparison of anionic and cationic inhibitors. Journal of plant physiology, 152(6), 696-702. https://doi.org/10.1016/S0176-1617(98)80032-1

Gao, Z. J., Liu, J. B., \& Xiao, X. G. (2011). Purification and characterisation of polyphenol oxidase from leaves of Cleome gynandra L. Food Chemistry, 129(3), 1012-1018. https://doi.org/10.1016/j.foodchem.2011.05.062

Guo, L., Ma, Y., Shi, J., \& Xue, S. (2009). The purification and characterisation of polyphenol oxidase from green bean (Phaseolus vulgaris L.). Food Chemistry, 117(1), 143-151. https://doi.org/10.1016/j.foodchem.2009.03.088

Han, Q. Y., Liu, F., Li, M., Wang, K. L., \& Ni, Y. Y. (2019). Comparison of biochemical properties of membrane-bound and soluble polyphenol oxidase from Granny Smith apple (Malus× domestica Borkh.). Food Chemistry, 289, 657-663. https://doi.org/10.1016/j.foodchem.2019.02.064

He, J., Yuan, J., \& Li, W. (2015). Enzymatic properties of polyphenol oxidase from Dysosma verispellis(Hance.) M. Cheng. Food Science, 36(13), 137-142.

Ioniţă, E., Gurgu, L., Aprodu, I., Stănciuc, N., Dalmadi, I., Bahrim, G., \& Râpeanu, G. (2017). Characterization, purification and temperature/pressure stability of polyphenol oxidase extracted from plums (Prunus domestica). Process Biochemistry, 56, 177-185. https://doi.org/10.1016/j.procbio.2017.02.014

Kim, S. L., Kim, S. K., \& Park, C. H. (2004). Introduction and nutritional evaluation of buckwheat sprouts as a new vegetable. Food Research International, 37(4), 319-327. https://doi.org/10.1016/j.foodres.2003.12.008
Liu, L., Cao, S., Yang, H., \& Qi, X. (2015). Pectin plays an important role on the kinetics properties of polyphenol oxidase from honeydew peach. Food Chemistry, 168, 14-20. https://doi.org/10.1016/j.foodchem.2014.07.064

Ma, X., Liu, C., Liu, X., \& Xu, W. (2016). Purification and Property of Wheat Polyphone Oxidase. Journal of the Chinese Cereals and Oils Association, 31(5), 11-16.

Palma-Orozco, G., Ortiz-Moreno, A., Dorantes-Álvarez, L., Sampedro, J. G., \& Nájera, H. (2011). Purification and partial biochemical characterization of polyphenol oxidase from mamey (Pouteria sapota). Phytochemistry, 72(1), 82-88.

https://doi.org/10.1016/j.phytochem.2010.10.011

Siddiq, M., \& Dolan, K. D. (2017). Characterization of polyphenol oxidase from blueberry (Vaccinium corymbosum L.). Food Chemistry, 218, 216-220. https://doi.org/10.1016/j.foodchem.2016.09.061

Song, Y., Wang, M., Han, X. (2020). Ultrasonic Assisted Extraction and Hypoglycemic Activity in Vitro of Chlorogenic Acid from Fagopyrum Esculentum Moench Leaves. Food Science and Technology, 45(07), 242-249.

Wu, M., Huang, Y., Yao, Y., \& Huang, Y. (2017). Characterization of crude polyphenol oxidase isolated from Camellia sinensis var. assamica cv. Mengku. Journal of Zhejiang University (Agriculture and Life Sciences), 43(5), 579-588. http://www.zjujournals.com/agr/EN/10.3785/j.iss n.1008-9209.2017.02.121

Yu, Q., Fan, L., \& Duan, Z. (2019). Five individual polyphenols as tyrosinase inhibitors: Inhibitory activity, synergistic effect, action mechanism and molecular docking. Food Chemistry, 297, 124910. https://doi.org/10.1016/j.foodchem.2019.05.184

Zaini, N. A. M., Osman, A., Hamid, A. A., Ebrahimpour, A., \& Saari, N. (2013). Purification and characterization of membrane-bound polyphenoloxidase (mPPO) from Snake fruit [Salacca zalacca (Gaertn.) Voss]. Food Chemistry, 136(2), 407-414. https://doi.org/10.1016/j.foodchem.2012.08.034

Zhu, F. (2016). Chemical composition and health effects of Tartary buckwheat. Food Chemistry, 203, 231245. https://doi.org/10.1016/j.foodchem.2016.02.050

Zhu, J., Kong, D., Li, M., \& Zheng, G. (2020). The studies on the enzymatic characteristics of polyphenol oxidase and its influence factors in two kinds of fresh fruits of Lycium barbarum L. Plant Physiology Journal, 56 (3), 382-388. 